Editorial

\title{
Announcing the Atmosphere 2018 Travel Award for Young Investigators
}

\author{
Atmosphere Editorial Office
}

MDPI, St. Alban-Anlage 66, 4052 Basel, Switzerland

Received: 16 April 2018; Accepted: 16 April 2018; Published: 16 April 2018

With the goal of recognizing outstanding contributions to the field of atmosphere sciences by early-career investigators, including postdoctoral fellows, assistant professors, or equivalent, and assisting them in attending international conferences in 2018, at the beginning of this year the journal Atmosphere accepted nominations for the 2018 Travel Award for Young Investigators. Over 70 nominations were received and were evaluated by a panel of judges comprised of Atmosphere Editorial Board Members.

We are excited to announce the two winners: Dr. Yue Zhang and Dr. Lucas Henneman. They will be supported with up to 800 Swiss Francs (CHF) each towards their travel expenses to attend international conferences in 2018.

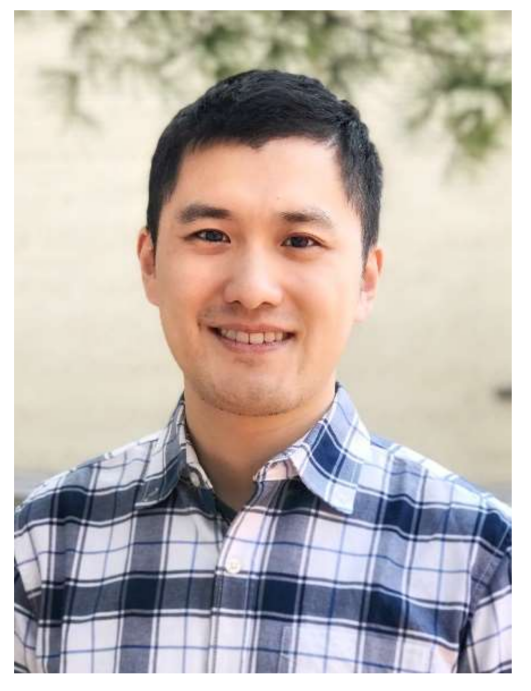

Dr. Yue Zhang

Dr. Yue Zhang is an U.S. National Science Foundation (NSF) postdoctoral fellow researcher at the Department of Environmental Sciences and Engineering in the Gillings School of Global Public Health, University of North Carolina at Chapel Hill, NC, USA.

He received his Ph.D. from Harvard University in May 2015 working at Professor Scot Martin's lab. His focus was on characterizing the physicochemical properties and phase state of organic aerosols (OA) with various techniques. Some of his work involved developing a novel technique to measure the in-situ viscosity of submicron particles, which was the basis of several additional studies by various research groups. He also participated in a field campaign in the Amazon rainforest and worked with collaborators to study the physicochemical properties of OAs. These results have been published in leading journals such as Nature Geoscience and Chemical Sciences. 
He received an NSF postdoctoral fellowship to conduct research with Professor Jason Surratt at the University of North Carolina at Chapel Hill. His research has covered both theoretical and applied atmospheric chemistry, including studying physicochemical properties, aerosol phase states, multiphase chemistry leading to secondary organic aerosol (SOA) formation, and the climate effects of OA. His recent work has shown that the phase state of SOA can potentially have important implications on multiphase chemistry involving the formation of isoprene-derived SOA. Currently he is leading multiple research projects in collaboration with several renowned institutions including MIT, Aerodyne Research, Boston College, Stony Brook University, and the University of California, Berkeley.

To date, he has been invited by the National Oceanic and Atmospheric Administration (NOAA) to perform proposal reviews and has conducted peer-reviews for multiple journals in the atmospheric chemistry field. His research also has received multiple recognitions including participation in the Atmospheric Chemistry Colloquium for Emerging Senior Scientists (ACCESS) and the excellent presentation award at the American Chemical Society (ACS) national meeting.

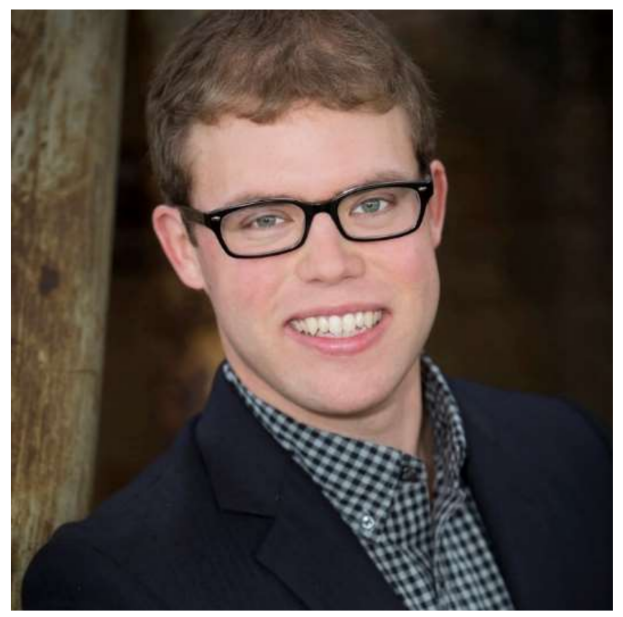

Dr. Lucas Henneman

Dr. Lucas Henneman is a postdoctoral fellow in the Biostatistics Department at the Harvard School of Public Health in Boston, Massachusetts, USA.

His research addresses questions of accountability; hundreds of billions of dollars have been spent throughout the world to clean up the air-to what level do the benefits justify the costs? Have we achieved what we set out to accomplish, or is there more work left to do? Lucas's current research is particularly focused on changes in emissions, air quality, and public health attributable to regulations on power plants.

Lucas earned his Ph.D. in 2017 and his Masters in 2014, both in Environmental Engineering from Georgia Tech in Atlanta, GA, USA, where he was a National Science Foundation Graduate Research Fellow and Georgia Tech President's Fellow. His thesis work used statistical and chemical transport modeling approaches to investigate the impact of the United States' 1990 Clean Air Act Amendments. He continues to combine modeling approaches to investigate nationwide changes in the health outcome rates associated with emissions reductions.

He is excited to present his work at the 36th International Technical Meeting (ITM) on Air Pollution Modeling and its Application in Ottawa, Ontario, Canada in May 2018. His presentation, entitled "Ozone in the eastern United States: production efficiency variability over time and between sources" will explore the relationships between rural and urban ozone concentrations and emissions changes at power plants and mobile sources.

Outside academic research, he enjoys playing piano and guitar and getting outside to bike, run, and play Spikeball. 
On behalf of the Atmosphere Editorial Board Members and editorial staffs, we wish to congratulate the two outstanding young investigators for their accomplishments.

Conflicts of Interest: The authors declare no conflict of interest.

(C) 2018 by the author. Licensee MDPI, Basel, Switzerland. This article is an open access article distributed under the terms and conditions of the Creative Commons Attribution (CC BY) license (http:/ / creativecommons.org/licenses/by/4.0/). 